\title{
Job Satisfaction and Quality of Work Life As a Commercial Flight Crew - A Review
}

\author{
Farah Azwa Mat Tiya ${ }^{1}$, Siti Nur Mariani Mohd Yunos ${ }^{1 *}$ \\ ${ }^{1}$ Department of Aeronautical Engineering, Faculty of Mechanical and Manufacturing Engineering, \\ Universiti Tun Hussein Onn Malaysia, 86400 Parit Raja, Johor, MALAYSIA \\ *Corresponding Author
}

DOI: https://doi.org/10.30880/paat.2021.01.01.002

Received 24 September 2021; Accepted 11 November 2021; Available online 21 December 2021

\begin{abstract}
The rapid growth of aviation industry resulted in a growing pilot demand globally from year to year. The increasing rate of pilot employed triggers all airliners to meet the needs of the organization that affect job satisfaction. Now, much attention has been given to the issue regarding quality of work life as flight crew by the management in the aviation sector as it is pertains to employee behaviour. Job satisfaction of flight crew describe on how well the job provides fulfilment and it serves as a source or means of enjoyment to every flight crew. Job satisfaction is important as it represent the degree to which flight crew feel positively or negatively about their job. There are many studies conducted to show the level of working satisfaction. However, not many studies have clearly demonstrated and discussed the quality of work life as a flight crew working in aviation industry. Therefore, this study aims to highlight the quality of work life as a flight crew working in aviation industry. All data from books, journal and articles were analysed. The result revealed that the job meaningfulness factor has the greatest impact on job satisfaction among flight crew working with commercial airlines in aviation industry. On the other hand, the lowest satisfied aspect among flight crew is related to reward and fairness aspect.
\end{abstract}

Keywords: Job satisfaction, aviation, flight crew, airlines

\section{Introduction}

Aviation has started in 1903 and since then, air travel has blossomed at many countries around the globe. Aviation industry plays a significant role in facilitating economic growth, particularly in developing countries. It has been one of the most competitive industries and has a high level of importance in the increment of tourism activities as well as enabling international trades and cooperations. Furthermore, the existence of LCCs has a positive impact on demand for domestic and international destinations $[1,2]$. Significant expansion can be observed and there are many airports that are now serve as important air travel hubs and offer good infrastructure to support the aviation sector.

Rapid growth in aviation industry has resulted in a higher pilot demand. Flight crew employment rate was positive, particularly before Covid-19 outbreak. Unfortunately, the outbreak put the growth of the aviation industry on temporary pause. As the consequences, many airlines in the world had to undergo restructuring. Despite a historic number of pilot being lay off around the world and some airlines declaring losses during the pandemic, industry experts believe that a pilot shortage will remain as the aviation industry prepares for a long term recovery from the pandemic [3].

Typically, the number of pilot needed per aircraft is primarily determined by aircraft utilization. At least two or more pilots are required to be on duty in the same flight deck. As a flight crew, pilot predominantly spend most of their time to fly the aircraft and they are the one who are fully responsible for the safe flight and lives of passengers onboard the aircraft. The human aspect is critical in maintaining or improving safety. Therefore, the importance of the human factor in aviation safety and effectiveness is generally acknowledged.

On the other hand, the relevance of job satisfaction to pilot is an issue that has been widely studied. The popularity of this field of study can be attributed to the importance of job satisfaction to the physically and mentally well-being of 
pilots. Job satisfaction can be described as a person's affective attachment to an individual job either in its entirety or with regard to particular aspects seen as facet job satisfaction [4]. A higher level of job satisfaction can boost a positive quality of work life as a pilot and therefore, benefiting the airlines as this will help in improving organizational performance.

In addition, job satisfaction plays a vital role in fulfilling a pilot's career goals. Job satisfaction is also equally significant for organization that particularly work in a team-based environment or in a workplace comprised of employees who work independently. The best and highly motivated workers in a company will continuously provide high quality work, extremely productive and are capable of overcoming challenges. Helping all workers maintaining a high level of job satisfaction can help keep workers stay committed to working hard and contribute as much value to the organization as possible. Since job satisfaction can be regarded as an important contributor to various aspects of work performance, this paper presents a review on factors that contribute to job satisfaction among active flight crew working with commercial airlines.

\section{Methodology}

In conducting a review, several phases have been executed and every phase is explained thoroughly in the following subsections.

\subsection{Preliminary Study}

This step involves the process of selecting a study title. Title selection research is done based on problems identified through articles, websites, news and reports. The chosen topic identified for this study is related to quality work life of a flight crew. Problem statement was discovered through readings for issues that have existed among flight crew. Meanwhile, the objective of this study is to discover factors affecting the flight crew's satisfaction working with commercial airlines through a review.

\subsection{Searching the Literature}

This phase consist of searching the literature and making decisions about the suitability of material to be considered in the review. Effort is taken to be as comprehensive as possible in order to ensure that all relevant studies be it published and unpublished are included in the review. The source of an online article is also an important element to support the reliability of an article. This is because original authors must validate their information sources through links and citations in order to publish academic journal online. This makes online journals and articles entirely credible and authoritative as it allow readers to verify the facts from original sources. For this study, most of the paper were retrieved from websites as such ScienceDirect and Multidisciplinary Digital Publishing Institute (MDPI) since the articles found on these websites are peer-reviewed scholarly articles. Additionally, papers from ResearchGate and Academia.edu were also referred as these websites are recognized as a platform that encourage researchers to share their publications with the community.

\subsection{Assessing the Quality of Literature}

It is important to assess the applicability of the materials identified in the previous step and screen the sources to determine the relevance [5]. Therefore, a set of predetermined rules were set to serve as a basis for including or excluding certain articles. In this study, most journal papers are particularly related to the aviation sector and job satisfaction. Considering that the main focus is aviation industry in Thailand, a journal paper is chosen if it has a relation to flight crew and aviation industry in this specified country. In addition, no limit was set on the publication year.

Based on the search, the selected journals were published between year 1994 to 2020 and they belong to the Field of Research (FoR) of 'job satisfaction' and 'aviation industry' in Thailand. Only papers with selected key phrase were chosen. For example, if the words such as 'aviation', 'aviation industry', 'aviation sector', 'airline', 'flight crew', 'job satisfaction', 'quality of work life', and 'pilot' existed in the research's title, abstract, or keyword section, the article or journal were selected to be as the instrument for this study. The use of specific phrases when searching for sources is necessary to keep the number of journal examined to a limit. Otherwise, the validity of the research paper is not in accordance with this study and the goal of identifying characteristic that lead to job satisfaction will not be achieved. Overall, a total of 100 journal articles were identified.

\subsection{Extracting Data}

Generally, this phase involves gathering or extracting necessary information from each article and evaluating what is relevant to the topic of interest. According to [6], the type of data that should be recorded is strongly influenced by the initial study objectives. Therefore, important information such as when, by whom, where the primary study was conducted, the research methodology and the study findings were extracted.

\subsection{Analysing and Synthesizing Data}


In this phase, data from the selected articles were collated, summarized, aggregated, organized and evidences extracted from those articles were compared. It is important that the data is structured in a way that suggest a new contribution to the existing research and the review provide a sound conclusion to make sense of what is already known about a topic.

\section{Results and Discussion}

A literature search was conducted for studies that evaluated the factors contributing to job satisfaction among flight crew working in aviation industry. All literature searches were conducted of ScienceDirect, ResearchGate, Academia.edu and MDPI.

\subsection{Descriptive Analysis}

Overall, 150 articles were found when searching for articles on quality of work life as a flight crew and job satisfaction that relate to aviation industry in ScienceDirect. Another 12 articles were discovered in MDPI. Next, when searching on Academia.edu, 16 additional articles were found. There were also 3 articles found while searching in ResearchGate. The studies reviewed in Academia.edu and ResearchGate were included as the argument was relevant. In summary, a total of 181 journal articles were initially discovered.

After reviewing the abstract for relevance, total of 100 articles were included in this review with the majority of the paper were studies found in Thailand. The focus of most studies was to evaluate the factor contributing to working satisfaction meanwhile, the goal of smaller group of studies was to evaluate the quality of work life as a flight crew with commercial airline. Many articles found during the search were not included in the review since they report the job satisfaction in another profession in aviation industry. Majority titles were broad descriptors of aviation industry, flight crew and airlines but the titles did not indicate the results relating to the factors contributing to job satisfaction with flight crew. All searches were limited to English language.

In contrary, there was no limit in publication year. From the search, the number of publications regarding this topic has continued to increase from year 1994 to 2020. This indicate a positive trend for aviation industry as the flight crew's job satisfaction is getting more attention among researcher.

Furthermore, some researchers have a strong contribution in the field of job satisfaction and aviation field. Table 1 shows the name of author that have strong contribution to the aviation field with at least 3 publications. Other than that, the share of authorship or authorship per publication is often discussed in the literature as an indicator of collaboration. Table 2 provides the authorship pattern involved in this study.

Table 1 - Researcher whom have authored at least 3 publications in related topics

\begin{tabular}{cc}
\hline Author Name & No of publications \\
\hline Iratrachar Amornpipat & 7 \\
Thamarat Jangsiriwattana & 7 \\
Nisara Paethrangsi & 6 \\
Tawee Jamjumrus & 5 \\
Chonlada Choovanichchannon & 5 \\
Kanitha Kaewpoungngam & 4 \\
Mai Ngoc Khuong & 3 \\
Sinnop Theprugsa & 3 \\
Hoang To Uyen & 3 \\
\hline
\end{tabular}

Table 2 - Authorship groups

\begin{tabular}{ccc}
\hline Type of authorship & Percentage & No of articles \\
\hline One authorship & $30.00 \%$ & 30 \\
Two authorship & $57.00 \%$ & 56 \\
$\geq$ Three authors & $14.00 \%$ & 14 \\
\hline
\end{tabular}

In addition, most of the retrieved articles were sourced from higher education institutions. However, there were also reports released by the non-institutional organization. Table 3 shows the list of organizations and higher education institutions that have significant contribution to this study. Lastly, this study also covers factors of job satisfaction of flight crew actively working either in full service airlines or low cost carriers. Table 4 presents the summary of airlines studied in the reviewed literatures. 
Table 3 - List of institutions and organizations

\begin{tabular}{cc}
\hline University & Organization \\
\hline Kasem Bundit University, Thailand & National Institute Development Administration, Thailand \\
Silpakorn University, Thailand & Civil Aviation Authority of Thailand (CAAT) \\
Suan Sunandha Rajabhat University, Thailand & International Air Transport Association (IATA) \\
Durakij Pundit University, Thailand & \\
Thammasat University, Thailand & \\
Mahidol University International College, Thailand & \\
Srinakharinwirot University, Thailand & \\
\hline
\end{tabular}

Table 4 - List of commercial airlines related to this study

\begin{tabular}{cc}
\hline Full service airlines & Low-cost carriers \\
\hline Thai Airways & AirAsia Thailand \\
Bangkok Airways & AirAsia X Thailand \\
& Bok Air \\
& Thai Lion Air \\
\hline
\end{tabular}

\subsection{Key Findings on Job Satisfaction Factors}

A total of 100 papers have provided a strong basis for discussion related to job satisfaction as a flight crew working with commercial airlines. These paper were analysed and as the result, 6 factors that describe the job satisfaction were identified. These factors are indicated in Table 5. The result shows that the level of job satisfaction is different for each factor.

Table 4 - List of factors contributing to job satisfaction

\begin{tabular}{ll}
\hline \multicolumn{1}{c}{ Factor } & \multicolumn{1}{c}{ Description } \\
\hline 1. Human resource management (HRM) & Activites that prmotore self-improvement are available \\
& Training opportunities and courses are plentiful \\
& Promotion opportunities \\
& Worker welfare \\
& Working relationship with employer \\
& Co-worker relationships \\
& Motivation in organization \\
& Cooperation between top management and employee \\
& Pay is commensurate with job scope \\
& Reward and recognition \\
& Flight duty allowance \\
& First aid kit availability in the aircraft \\
& Medical coverage for flight crew \\
& Work life balance \\
4. Health & Health check \\
& Exposure to safe working environment \\
& Safety awareness of individual on duty \\
& Airworthiness of equipment \\
5. Safe working environment & Work scope is equivalent with qualification \\
& Pride with the job itself \\
& Job security level \\
6. Job meaningfulness & Appropriate working hours \\
& Capable in performing assigned work at certain work time \\
&
\end{tabular}

\subsubsection{Human Resource Management}

Generally, the relationship that an employee has with his or her superior is regarded as the most important aspects of workers' relationship with the company or an organization [7]. 65\% of the articles were in agreement with HRM being the determinant to job satisfaction among flight crews. Many authors agreed that often employee behaviour has been claimed as the reflection of how they are treated by the company. HRM policies are the reflection of the company's 
vision, professional learning and development, adequate compensation and benefits [8]. Its success is determined by how well it attracts, recruits, motivates and retains skilled flight crew.

One of the aspect that contribute to a good relationship between flight crew and HRM is the promotion opportunities. In many organization, HRM is responsible to grant all entitled flight crew the rights together with plentiful opportunities to grow in terms of career prospect within the flying organization. Career development can be described as a planned and systematic process that aims to strike a balance between flight crews' career goals and the organization's workforce requirements. It corresponds to initiatives in assisting flight crew in making career development such that it is in line with the organization's objectives and strategic planning.

It is worth to mention that career development can be simplified as a chance for every flight crew to continue participating in more extensive and diverse practices in terms of networking and training which result in improving existing skills, developing new skills, taking on bigger responsibility, enhancing their position and earning higher income. This is in agreement with [9] who claimed that opportunities to gain experience and improve skills while working have an impact on job satisfaction.

As a flight crew, there are countless modules and assessments that need to be completed during the formal and informal trainings. The provided courses are the example of initiatives initiated by HRM for flight crews' future selfimprovement. HRM supports in career development is important as this will assist flight crews to create more realistic career development goals. This element is also important as it can increase flight crews' motivation and productivity.

Constant periodic training and courses are one of the strategies taken by HRM in many airlines as a step to improve flight crews' skills and sharpen their knowledge. Every pilot must undergo trainings and passes several assessments such as base training, base check, line training and line check. Every flight crew will prepare themselves with all required theories as well as psychomotor skills before they attend their flight check assessment. Through all necessary checks and flight simulation training provided by the HRM in the organization, it can enhance the pilots' navigation skills and increase their performance. Such approaches may enable flight crews to fully utilize the available training opportunities and thus performing task more efficiently and effectively. The probability for an incident to occur is low since the training helps to equip flight crews with preparedness to practice emergency procedures or unusual situations from the safety on the ground. Ongoing flight training and career development courses are essential to ensure job continuity as well as maintaining good order and discipline on board the aircraft.

\subsubsection{Social Relation}

Social relation refers to a healthy social relationship with team, supervisors and other organizational members, and it is one of the top factors that contribute to job satisfaction among flight crew [8]. A total of $73 \%$ of the articles reviewed have mentioned that job satisfaction can be measured through the ability to have a good social relation.

It was found that, the most prominent aspects related to job satisfaction among flight crews is co-worker relationship. Working as a flight crew requires someone to work in a team and have an excellent communication at all times. Without a good co-worker relationship, it is quite impossible for a flight crew to work systematically on board the aircraft on a day to day basis. A healthy co-worker relationship can motivate flight crew and increase their morale. Flight crew can focus on work tasks more effectively if they casts aside relationship issues. When tasks are highly and mutually interrelated; particularly in piloting sector where many pilots must collaborate to ensure each aircraft operates safely to every destinations, forming a team between pilots is necessary in order to ensure the level of coordination and information sharing among the crew is successful. Therefore, teamwork is an essential element in job satisfaction. By having a good co-worker relationships, flight crew can understand each other and able to perform work together more effectively in a team for a more satisfying environment.

Besides that, major air carrier also emphasize a good social relation between top management and flight crew. This indicates a strong social relation with superiors escalate flight crews' satisfaction towards their job. Flight crews believe that job satisfaction is at a high level when necessary attention is given. Wonderful relationship between subordinate and employers also makes them feel needed and they are an important asset in the organization. Providing a sense of belonging for the employee and recognition of job well done go a long way in making flight crews feeling more excited and enjoy their work. Similarly, job enrichment and sharing power encourage flight crews to stay motivated at work. They would believe that they are being trusted and supported from individuals they are working with.

\subsubsection{Reward and Fairness}

The fact that pilots are one of the top earners in the world is not a big surprise for everyone. Most people are fascinated by flight crew salaries either as a factor to become a pilot or because it is known that they are among the highest salaries benefactor. However, this aspect is categorized as the lowest contributor to job satisfaction factor by most flight crew. Pay correlates with job satisfaction and overall well-being but those who already reached a standard level of comfortable living may find it as less important.

Wages, bonuses, compensation as well as recognition are all part of a workers' reward and fairness aspect. Although job satisfaction of flight crew was at a high level, reward and fairness aspect are at a slightly low level. This definitely in contrast with the current economic expense of living. Internally balanced, externally competitive and individually 
stimulating reward schemes and policies are absolutely essential for all flying flight crew. Well balanced allowance was reported to produce short-term energy boosts among flight crew which may have unforeseen implications in their working performance.

The non-stop competition among airlines prompted for cost cutting and efficiently balancing both short and long terms performance. Airlines must reconsider the new flying allowance that to a more acceptable range by flight crews as an initiatives to prevent more serious problems from occurring, such as higher flight crew turnover. If the airlines keep neglecting the raising issue, it can affect flight crew satisfaction. Good reward and fairness dimension have large and direct impact on job satisfaction. Every flight crew must receive pay including benefits, allowance, reward and recognition that is commensurate with the task given and receive fair treatment from the organization as well as receive respect from the stakeholders.

\subsubsection{Health Aspects}

Health aspects also play a significant role in job satisfaction in every working sector and yet health-wise is the second least satisfy factor in most journal articles that has been reviewed. There were just only $22.3 \%$ articles agreed that health is one of the contributing factor to job satisfaction among flight crew working in aviation industry.

The health aspect is a priority in work and if it is satisfied, it will lead to a sense of job satisfaction. Poor work life balance is the most highlighted element by flight crew working in commercial airlines. Some pilots are required to work for more hours than the prearranged amounts which eventually leads to a loss of working efficiency, a higher stress level, sleeps deficiency and pressure from family [10]. For flight crew who have families including children to care for, the situation is even tougher as it can lead to worst work-life balance in terms of mental and physical health.

A pilot's job is demanding yet stressful. Basically, a pilot works under a great pressure of stress on a daily basis. This is because, they are responsible for passengers' live and must memorize countless theories from their training. They are also bonded to countless assessment that took a lot of their time. Additionally, no two flights are identical plus they need to work on odd hours. Therefore, pilots need to stay focus and be ready for any emergency that might occurs during their flight.

Meanwhile, lack of appropriate sleep is one of the leading reasons of fatigue in the airline industry. Pilots' schedules are rarely consistent from day to day which could contribute to sleep deprivation. Frequent flyers are more likely to experience insomnia and loss of appetite when their biological clock turns against the environment. As a result, flight crew were extreme cautious when returning to their based after a long haul flight.

On top of the pressures of flying, many pilots spend days away from home especially on international flights. Although free traveling to different regions of the world while experiencing other cultures can be exciting, it can give impact to the work-life balance of a pilot since it is a tiring process. A strong work-life balance can prevent a pilot from feeling dissatisfied with their job and life. Without a good work-life balance, it is easy to experience burnout.

\subsubsection{Safe Working Environment}

It can be observed that the safe working environment aspect is moderately satisfied by flight crews. A more pleasant work environment can boost work's performance and increase job satisfaction. This is supported by $41.3 \%$ articles that draw attention to safe working environment aspect could affect flight crews' job satisfaction. The most mentioned facet in this factor is on the airworthiness of equipment and includes cockpit and cabin crew as well as the relevance of the maintenance of aircraft.

It is absolutely essential to provide flight crew with a work environment that is conducive to their overall development. Safe and healthy working environment is important as it helps flight crew to cater both personal comforts and facilitates them in doing a good job. The reason to a moderate job satisfaction among flight crews in term of airworthiness of the equipment is mainly due to technical issues and it affecting their safety and sometimes weather conditions could even be out of aircraft's operational limits. Modern aircraft are reliable machines but that does not imply they are flawless. Even though flight crew are well trained to handle the flight in any situation but, this situation still give pressure to pilot. Technical issue such as poor airworthiness equipment may have a direct impact on the pilot and thus it can affect pilot's job satisfaction. In terms of weather, in aviation it can be one of the largest threats when it comes to safety. This elements can add significant stress and safety issue to an operation and therefore, this aspect lead flight crews to rate it moderately.

There are times where pilots may be flying with inexperience crew members [11]. Good relation, synergy and teamwork is vital to create a safer and effective operation. Decision making should be made by the team and not by a single individual. Allowing crew to give inputs and suggestions creates a good and safe working environment for pilots especially when flight crew need to encounter an abnormal situation. Having a good relation and switching information among flight crew is important to ensure the safety of every lives. Regardless how serious the challenge, the pilot need to be able to handle it.

Next, airlines should have acknowledge that flight crews spend most of their time at work and thus they should take steps to ensure that the working environment are pleasant and stress-free for them. Efforts such as enhancing the training 
on Crew Resource Management (CRM) for flight crew personnel can be a good effort from the airlines to assure a safe and efficient operation, reducing error, avoiding stress and increase efficiency [12].

\subsubsection{Meaningfulness}

$84 \%$ of the articles reviewed indicate that a majority of researcher in this area are affiliated with job meaningfulness. There are many characteristic that could describe job satisfaction in term of job meaningfulness wise. For instance, job security, work scope given equivalent with qualifications and appropriate working hours are the related characteristics. The nature of work, particularly in a sense of pride to complete their job as a flight crew is one of the highlighted contributors to job meaningfulness. This dimension leads in the highest degree of job satisfaction.

Job meaningfulnesss also describes the importance of the job from worker's perception. According to [13], job meaningfulness can be defined as an employees' feelings about their job in terms of its importance, pride and excitement. The job that every flight crew do is inextricably connected to their quality of work-life. It is found that majority of flight crew want to be recognised for their expertise and professionalism.

Some flight crews had wished to work as a flight crew since they were little. This indicates that they are very passionate and optimist in becoming a flight crew. Some pilots also love their jobs and consider it a calling and not just a way to make a living. Basically, when an individual being happy at work and loving what they do is an overall productivity booster and thus it can enhance individual's performance. An optimistic flight crew are more likely to be motivated, able to learn faster and make fewer mistake. This aspects is so important to every flight crew as they need to ensure a safe operation at all time. This can be seen from different point of view whereby, a flight crew who are really passionate in performing their task tend to broaden their network to maximum level and improve many skills such as communicating and soft skill.

Job security is also important in describing job meaningfulness. This is because, it is important for a flight crew to feel comfortable and secure with their employment. In addition, majority of the flight crew also expressed their satisfaction in term of the job scope. Flight crews agree and emphasize that the job scope given to them is within their qualification and capabilities. This aspect has proven that to work as a pilot especially in commercial airlines, someone need to meet specific requirement set by the organization. Flight crew that have knowledge and information about their job scope will be able to perform better and this can give impact on job satisfaction.

\section{Conclusions}

Employees is the key resource in a working organization. Job satisfaction is a multidimensional concept that has been studied in numerous perspective such as organizational psychology, business, management and human resource. Moreover, job satisfaction among service employee is one of the most studied topic in human resources research.

In general, job satisfaction is the extent to which an employee is satisfied and felt happy with their job, to the point of becoming an employee whom willingly to perform work at an optimum level. Factors that can influence job satisfaction can changed over time as the fluctuation could be attributed to changes within the workplace as well as economic, demographic and social trends.

Overall, the job satisfaction among active flight crew working particularly in aviation industry is influenced by six factors. These factors include job meaningfulness, social relation, HRM, safe working environment, health as well as reward and fairness. Job meaningfulness is recognized as the main factor for job satisfaction as flight crews want to be recognized for their professionalism. This is followed by a good social relation which describes the perception of having a healthy co-worker relationship between the team. The third factor is HRM and it indicates the opportunities to grow in terms of career development. The fourth factor is safe working environment and it refers to the airworthiness of equipment, cabin and cockpit. However, in terms of health aspects as well as reward and fairness, these two factors are least factors that can lead to a job satisfaction among flight crews. Lastly, these finding could help HRM in aviation organization to reconsider its policy and practices in order to gain sustainable advantage in the competitive market by improving the quality of work life of their flight crews.

\section{Acknowledgement}

The authors would like to thank Universiti Tun Hussein Onn for Tier 1 Grant Vot H770. The work described in this paper is part of a research carried out by Farah Azwa Mat Tiya for her undergraduate dissertation.

\section{References}

[1] J. Y. Chung and T. Whang, "The impact of low cost carriers on Korean Island tourism," Journal of Transport Geography, vol. 19, no. 6, pp. 1335-1340, 2011

[2] R. Belén, R. Myro and A. Galera, "Effect of low-cost airlines on tourism in Spain. A dynamic panel data model," Journal of Air Transport Management, vol. 3, no. 17, pp. 163-167, 2010

[3] G. Murray, "After COVID-19, aviation faces a pilot shortage," 2021. [Online]. Available: 
https://www.oliverwyman.com/our-expertise/insights/2021/mar/after-covid-19-aviation-faces-a-pilotshortage.html [Accessed 19 May 2021]

[4] C. Hoole and L. P. Vermeulen, "Job satisfaction among South African aircraft pilots," SA Journal of Industrial Psychology, vol.29, no. 1, pp. 52-57, 2003

[5] G. Paré, M.C. Trudel, M. Jaana and S. Kitsiou, "Synthesizing information systems knowledge: A typology of literature reviews," Information \& Management, vol. 52, no. 2, pp. 183-199, 2015

[6] Okoli, C. and K. Schabram, "A guide to conducting a systematic literature review of information systems research," Sprouts: Working Papers on Information Systems, vol. 10, no. 26

[7] A. Jayakumar, K. Kalaiselvi, "Quality of work life - an overview," International Journal of Marketing, Financial Services \& Management Research, vol. 1, no. 10, pp. 140-151, 2012

[8] I. Amornpipat, "An explanatory factor analysis of quality of work life of pilots," Psychology Research, vol. 9, no. 7,2019

[9] B. V. H. Gilmer, Industrial psychology. McGraw-Hill, 1966

[10] M. Malik, S. K. K. K. Alwi and M. Shamshir, "Marital status and work life balance: a case study of commercial pilots of Pakistan," Journal of Southwest Jiaotong University, vol. 55, no. 4, 2020

[11] "Rising number of inexperienced pilots may lead to more crashes," 2015. [Online]. Available: https://theconversation.com/rising-number-of-inexperienced-pilots-may-lead-to-more-crashes-39593 [Accessed 23 May 2021]

[12] H. Littman-Ovadia, E. Rass-Rothschild, "Character strengths of airline pilots: explaining life and job satisfaction and predicting CRM performance," Psychology, vol. 9, pp. 2083-2102, 2018

[13] P. E. Spector, Job satisfaction: application, assessment, causes, and consequences. SAGE Publications, 1997. 